\title{
Determination losses and estimate life of distribution transformers with three computational, measurement and simulation methods, despite harmonic loads
}

\author{
M.H. Amrollahi ${ }^{1}$, S. Hassani ${ }^{2}$ \\ ${ }^{1}$ Electrical Engineering Department \\ Urmia University of Technology ,Urmia, Iran, Amrollahi_mh @yahoo.com \\ ${ }^{2}$ West Azerbayjan Power Distribution Company, Urmia, Iran, sh592b@yahoo.com
}

\begin{abstract}
Transformers are the basic and valuable equipment of electricity network. Transformers correct function has important role in reliability of network .distribution transformers are designed for work at nominal frequency and full sinus current. Application of nonlinear loads in recent decades, such as power electronic loads, caused higher levels of harmonic. This kind of load can lead to creating heat, losses and therefore cause wear of insulation and aging of transformers. To prevent these problems, nominal capacity of transformers that will feed the nonlinear load, should be reduced.

In this paper the parameters affecting the loss of a single phase $15 \mathrm{KVA}$ transformers with harmonic loading measurement and will be calculated with standards then The transformers with harmonic loads are simulated in MATLAB software for calculating losses Finally, the obtained results are compared. The reduction of nominal power (Derating) and transformer life and flow rate limits and losses are calculated.
\end{abstract}

\section{Key words}

losses, harmonic loads, measuring transformer losses, transformer harmonic model

\section{Introduction}

Increasing nonlinear loads, harmonic distortion, and the issue of power quality problems in recent years has been an important debate. Nonlinear loads and equipment in the network that having nonlinear characteristic is the main cause of distortion in sinusoidal voltage and current waveform and changing of waveform can cause harmonic. With increasing nonlinear loads measurement, exact analysis of harmonics seems essential to prevent energy losses, injuries, and its destructive effects on the network equipment. In recent decades by increasing nonlinear loads, harmonic levels in distribution networks has greatly increased, and increases in harmonic load current cause additional losses and increases in winding hot spot temperature and stress on insulation, and finally reducing the useful life of insulation and transformer capacity .The aim of this paper to determine losses and estimate life of distribution transformers under harmonic loads with three computational, simulation and measuring methods . First loss and capacity useful life of transformer under harmonic loads are determined and then the distribution transformers losses have been compared with three, Computational, measurement and simulation methods in software environments

\section{Transformer losses in harmonic loads}

Transformer losses under linear and harmonic loads are divided two categories no load and loading loss.

$$
P_{T}=P_{N L}+P_{L L}
$$

Where $P_{L I}$ loading losses that is divided ohmic losses and eddy loss, $P_{N L}$ no load is due to voltage induced in the core and $P_{T}$ is total loss of the transformer.

Transformer losses in harmonic loads Transformer losses under linear and harmonic loads are divided two categories no load and loading loss

$$
P_{T}=P_{N L}+P_{L L}
$$

Where $\boldsymbol{P}_{L E}$ loading losses that is divided ohmic losses and eddy loss, $\boldsymbol{P}_{N L}$ no load is due to voltage induced in the core and $P_{T}$ is total loss of the transformer.

Loading losses: loading loss can be stated as follows:

$$
P_{L L}=P_{d \sigma}+P_{E C}+P_{O S L}
$$

$P_{d c}$ Is an ohmic loss due to coil resistance and $P_{E C}$ eddy current losses and $P_{O S L}$ is other eddy loss. The total losses $P_{O S L}$ and $P_{E C}$ refers to the total dispersion, it is calculated from ohmic losses minus of loading loss that obtained from short circuit test.ohmic losses, wending eddy loss and other losses is proportional to the current therefore in this paper effect of harmonic current is calculated.ohmic loss is proportional to square of the current therefore if the effective current increase because of harmonics the ohmic losses are increased.

$$
P_{\Omega}=R_{d c} \times I_{A}^{2}=R_{d c} \times\left(\sum_{h=1}^{h_{\max }} I_{h, m m s}^{2}\right)
$$

Eddy losses of coil with nonlinear load is changed with square of current and frequency

$$
P_{e c}=P_{e-R} \sum_{h=1}^{h=\max } h^{2}\left(\frac{I_{h}}{I_{R}}\right)^{2}
$$

Considering the above equation loss factor can be based on effective value of current 


$$
F_{H L}=\frac{\sum_{h=1}^{h=\max } h^{2} I_{h}^{2}}{\sum_{h=1}^{h=\max } I_{h}^{2}}=\frac{\sum_{h=1}^{h=\max } h^{2}\left(\frac{I_{h}}{I_{1}}\right)^{2}}{\sum_{h=1}=\max \left(\frac{I_{h}}{I_{1}}\right)^{2}}
$$

The harmonic loss factor for other eddy losses obtained from main component of effective current

$$
F_{H L-S T R}=\frac{P_{\text {OSL }}}{P_{\text {OSL }-R}}=\frac{\sum_{h=1}^{h=\max }\left[\frac{I_{h}}{I}\right]^{2} h^{0.8}}{\sum_{h=1}^{h=\max }\left[\frac{I_{h}}{I}\right]^{2}}=\frac{\sum_{h=1}^{h=\max }\left[\frac{I_{h}}{I_{1}}\right]^{2} h^{0.8}}{\sum_{h=1}^{h=\max }\left[\frac{I_{h}}{I_{1}}\right]^{2}}
$$

In fact in harmonic loads, eddy losses of coils and other eddy losses must be multiplied by above factors No load losses:

No load losses is caused from Foucault and hysteresis losses in the transformer core

$$
P_{N L}=P_{h}+P_{f}
$$

In this equation $P_{h}$ is a hysteresis loss and $P_{f}$ is Foucault losses, this loss proportional with frequency and maximum flux density in the core and are independent of load.

Numerous experiments show that increasing the core temperature is not a limiting factor in determining the permitted current in the transformer with nonlinear loads [2]. Because of the harmonic voltage, which typically are less than $5 \%$, we can use only the main components of the voltage for determining no load losses this has led to only a few errors and will be negligible

\section{Transformer capacity and life with harmonic loads}

In recent years, non-linear loads (computers, electronic power supplies, discharge lamps, rectifiers, motor controllers, and induction furnaces...) are increasingly into electrical networks. increasing use of such devices is created concern for power grid Number of non-linear loads that injected non-sinusoidal current into the network are increased, they has very growing trend. Nonlinear loads considerably causing disturbance, which can create harmonics and reduce the network capacity. In transformers, harmonic currents cause increase of Foucault flow and disorganization of leaking fields. More losses create more heat in transformers and transformer temperature increases that made damage or Extreme Burnout of insulation and reduce the useful life transformers or Transformer work under rated capacity (de-rate). One of the ways to overcome this problem is that the transformer design so strong and large to bear this kind of loss. Loading losses in linear load case and nominal conditions are shown (per unit):

$$
P_{L I-R}(p u)=1+P_{E C-R}(p u)+P_{\text {OSL }-R}(p u)
$$

$\boldsymbol{P}_{E C-R}$ : winding eddy losses in nominal condition $\boldsymbol{P}_{\text {OSL-R }}$ :other eddy losses in nominal condition $\boldsymbol{P}_{\text {LL-R: }}$ lodding losses
In non-linear and harmonic load:

$$
P_{L L}(p u)=I^{2}(p u) \times\left[1+F_{H L} \cdot P_{E C-R}(p u)+F_{F L-S T R} \cdot P_{\text {OSL-R }}(p u)\right]
$$

Therefore, the maximum allowable current for determine transformer nominal power reduction value is equal to:

$$
\mathrm{I}_{\mathrm{m} n \mathrm{x}}(p u)=\left[\frac{P_{I L-R}(p u)}{1+F_{I L} P_{B C-R}(p u)+F_{I L-S T R} P_{O S L-R}(p u)}\right]^{0.5}
$$

Therefore the maximum allowed current for decreasing rated power and capacity of transformers with harmonic load can be determined that this action be called derating.for estimate reduced transformer life,degradution rate of insulation material must considered $.50 \%$ reduction of transformer life is due by thermal stress is caused by harmonic currents. Most important factor in reducing the life of transformers is

$\theta_{H S}$ point temperature. Reduction of life and real life of a transformer can be calculated from the following relations:

$$
\operatorname{Life}(p u)=9.8 \times 10^{-18} \exp \left(\frac{15000}{\theta_{H S}+273}\right)
$$

Real Life $=$ Life $(p u) \times n o r m a l$ insulation life

\section{Determine and compare the losses in a transformer with two methods of measurement and calculation in harmonic loads}

\begin{tabular}{|c|c|c|c|}
\hline $\begin{array}{l}\text { Characteri } \\
\text { stic }\end{array}$ & value & Characteristic & value \\
\hline $\begin{array}{l}\text { Rated } \\
\text { power }\end{array}$ & $15 \mathrm{KVA}$ & $\begin{array}{l}\text { PRIMERY WIDING } \\
\text { RESISTENT }\end{array}$ & $435.12 \mathrm{OHM}$ \\
\hline $\begin{array}{l}\text { Rated } \\
\text { frequancy }\end{array}$ & $50 \mathrm{HZ}$ & $\begin{array}{c}\text { SECONDERY WIDING } \\
\text { RESISTENT }\end{array}$ & $0.0412 \mathrm{OHM}$ \\
\hline $\begin{array}{l}\text { Primery } \\
\text { voltage }\end{array}$ & 20000VOLT & NO LOAD LOSS & 120.12 WATT \\
\hline $\begin{array}{l}\text { Secondery } \\
\text { voltage }\end{array}$ & 231VOLT & FULL LOAD LOSS & 550.82 WATT \\
\hline $\begin{array}{c}\text { Rated } \\
\text { primery } \\
\text { current } \\
\end{array}$ & 0.75 AMP & $\begin{array}{c}\text { AVERAGE } \\
\text { ENVIRNEMENT } \\
\text { TEMPRETURE }\end{array}$ & $35 \mathrm{C}$ \\
\hline $\begin{array}{c}\text { Rated } \\
\text { secounder } \\
\text { y current }\end{array}$ & 65.2 AMP & $\begin{array}{l}\text { Permissible winding } \\
\text { temperature rise }\end{array}$ & $65 \mathrm{C}$ \\
\hline
\end{tabular}

Two transformers of the same specifications as are connected back to back was used in the experiment, this circuit fed by an autotransformer and in the output a harmonic load is placed amount of losses on both sides is measured and recorded by datalogger.

Table 2: technical characteristic of transformer 
The diffetrences of mesurment data that mesured by two device,transformers losses is achieved. Losses of each transformer is half the amount recorded. table 2 shows the result of measurment and calculation values for transformer losses

Table 2 Results of loss measurements for different loads

\begin{tabular}{|l|l|l|c|c|}
\hline $\begin{array}{c}\text { difference } \\
\text { calculations } \\
\text { with test } \\
\text { results(percent) }\end{array}$ & $\begin{array}{c}\text { Calculatio } \\
\mathrm{n} \text { result }\end{array}$ & \multicolumn{3}{|c|}{ Measured losses result(test result) } \\
\cline { 2 - 5 } & $\begin{array}{c}\text { Harmonic } \\
\text { losses }\end{array}$ & $\begin{array}{c}\text { Loss } \\
\text { Increase } \\
\text { (percent) }\end{array}$ & $\begin{array}{c}\text { Losses } \\
\text { with } \\
\text { harmonic } \\
\text { load }\end{array}$ & $\begin{array}{c}\text { Losses } \\
\text { with } \\
\text { sinusoida } \\
1 \text { load }\end{array}$ \\
\hline $1.86 \%$ & $152.9 \mathrm{w}$ & $7 \%$ & $150.1 \mathrm{w}$ & $141.4 \mathrm{w}$ \\
\hline $0.60 \%$ & $167.9 \mathrm{w}$ & $1 \%$ & $166.9 \mathrm{w}$ & $165.2 \mathrm{w}$ \\
\hline $1.56 \%$ & $188.3 \mathrm{w}$ & $21 \%$ & $185.4 \mathrm{w}$ & $153.5 \mathrm{w}$ \\
\hline
\end{tabular}

The above table shows the percentage difference between the calculations with test results is less than $2 \%$.

To calculate the reduction of transformer life $\theta_{a}=35^{c}$ and $\theta_{\text {TO-R }}=60^{\mathrm{C}}$ and Reference temperature $110^{\mathrm{C}}$ Be considered:

$$
\begin{aligned}
& \theta_{\text {TO }}=60 \times\left(\frac{758}{670.94}\right)^{0.8}=66.15^{\circ \mathrm{C}} \\
& \theta g=10 \times\left(\frac{637.9}{550.82}\right)^{0.8}=11.25^{\circ \mathrm{C}} \\
& \text { Life }(\mathrm{pu})=9.8 \times 10^{-18} \exp \left(\frac{15000}{112.4+273}\right)=0.784
\end{aligned}
$$

Real Life $=0.784 \times 30=23.5$ years

\section{Based on simulation results}

Transformers according figure 1 equivalent circuit is simulated are simulated and harmonic loads are modeled by connecting multiple current source with different frequencies

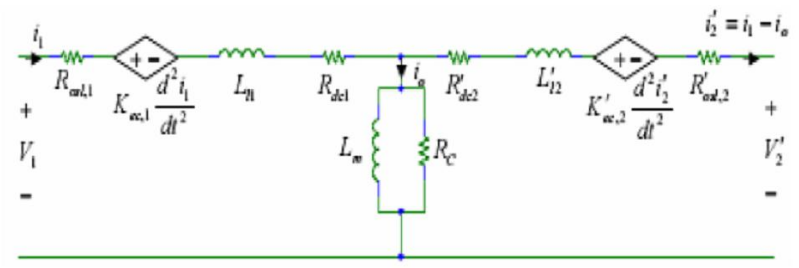

Figure 1. Transformer equivalent circuit in Harmonic environment

Table 3 shows Comparison of three methods applied with harmonic and sinusoidal load. The computational method is less accurate than simulation and measurement method .Because in computational method loss factor proportional to square of harmonic order also simulation with above transformer equivalent has acceptable accuracy.

The result show harmonic orders and there altitude directly impact on transformer losses also effect of harmonic load on ohmic losses and other eddy losses is low.

In calculation method eddy losses in coils estimated with square of frequency but this method standard not enough accurate. Simulation method with equivalent circuit in harmonic environment has enough accuracy.

\section{Conclusions}

this article has been shown that the effect of harmonic loads on the ohmic losses and other eddy losses were small, but its effect on winding eddy current losses is high. In computing, eddy current losses of coil increase with the square of frequency are considered and the standards in this field accuracy are not enough. Simulation methods using transformer harmonic equivalent circuit has good precision. The transformer hot spot temperature, strongly depend on size and winding eddy current distribution. Increasing transformer losses because of nonlinear load current cause increase in transformer temperature, burnout, and early fault in insulation and finally reduce transformers insulation life. Therefore, in these conditions is essential to avoid reducing transformer life, capacity (nominal power) of transformers will be reduced

\section{References}

[1] IEEE Std C57.110-1998, IEEE Recommended Practice for Establishing Transformer Capability when Supplying NonSinusiodal Load Currents

[2] A Girgis, E. Makram, J. Nims, "Evaluation of temperature rise of distribution transformer in the presence of harmonic distortion", Electric Power Systems Research, vol. 20, no.1, Jan 1990, PP.1522.

[3] Deniz Yildirim “ Measured Transformer Derating and Comparison with Harmonic Loss Factor Approach " IEEE Trans.on Power Delivery,Vol.15,No.1,January2000,pp.186-191 .

[4] S.B.Sadati, A.Tahani, M.Jafari, M.Dargahi, "Derating of transformers under Non-sinusoidal Loads", 11th IEEE International Conference on Optimization of Electrical and Electronic Equipment OPTIM 2008, Brasov, Romania, PP.263268.

[5] J. Faiz , M . B . B . Sharifian , S . A . Fakheri , E . SabetMarzooghi " Derating of distribution transformers for nonsinusoidal load currents using finite element method " Iranian Journal Of Science \& Technology, Transaction B,Vol.28,no.B3 ,pp.315-322.

[6] S.B. Sadati, A. Tahani, B . Darvishi, M. Drgahi, H . Youefi “ Comparison of Distribution Transformer Losses and Capacity under Linear and Harmonic Loads "PECon 2008,IEEE 2nd International Power and Energy Conference 2008,1-3 Dec.2008,pp.1265-1269 


\section{TABLE3 .Comparison of methods to determine losses}

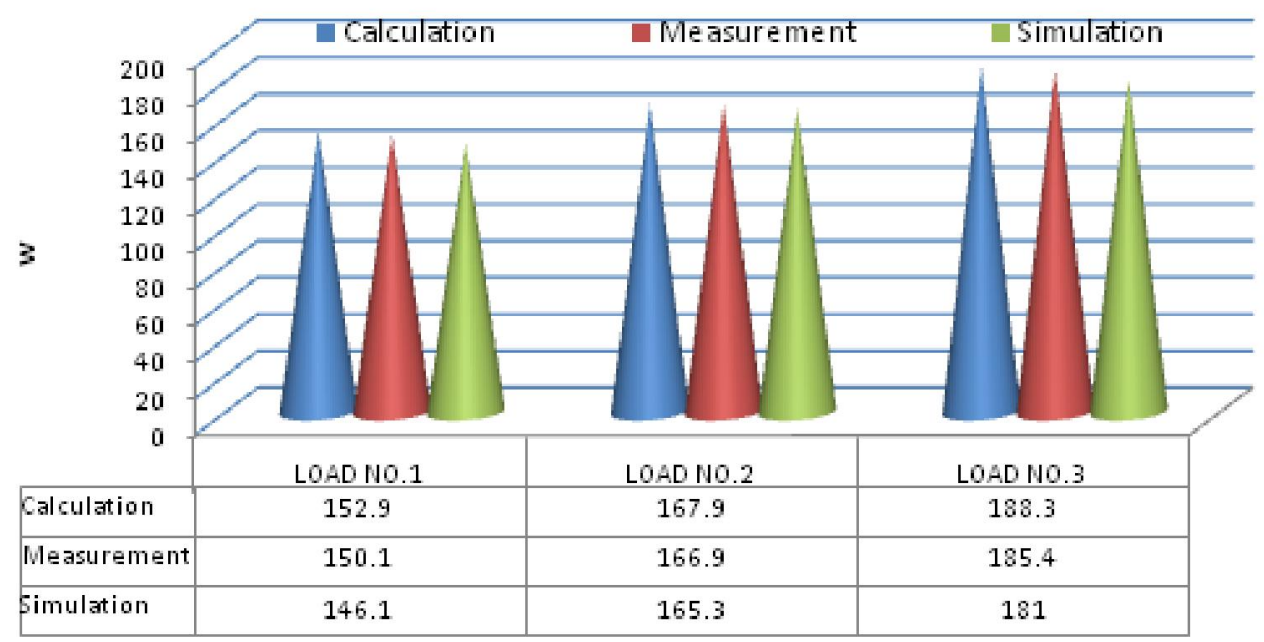

